\title{
UMA ABORDAGEM DE GESTÃO DE RISCOS PARA ATIVIDADES DE EDUCAÇÃO AMBIENTAL AO AR LIVRE
}

\author{
Rodrigo Cavasini ${ }^{1}$ \\ Rafael Falcão Breyer ${ }^{2}$ \\ Ricardo Demétrio de Souza Petersen ${ }^{3}$
}

Resumo: A Educação Ambiental ao ar livre integra atividades teóricas a atividades ao ar livre. Ao mesmo tempo em que essas atividades despertam o interesse da população podem expor os envolvidos a riscos desnecessários; desse modo, gera-se a demanda por esforços estruturados de gestão de riscos. Este trabalho relata a abordagem de gestão de riscos em atividades de Educação Ambiental ao ar livre desenvolvidas em disciplinas dos dois cursos de Educação Física. As avaliações indicaram êxito na gestão de riscos e ampliação de competências e percepção da relevância dos temas desenvolvidos. Enfim, uma abordagem que é constantemente avaliada e tem servido de modelo para propostas realizadas por outras instituições.

Palavras-chave: Educação Ambiental; Gestão de Riscos; Atividades ao Ar Livre.

${ }^{1}$ Pontifícia Universidade Católica do Rio Grande do Sul. E-mail: rcavasini@yahoo.com.br

2 E-mail: rfbreyer@gmail.com

${ }^{3}$ Universidade Federal do Rio Grande do Sul. E-mail: petersen@esef.ufrgs.br 


\section{Introdução}

Nas últimas décadas a degradação do meio ambiente e os impactos ambientais gerados pela ação inconsequente da humanidade atingiram escalas preocupantes. Dessa forma, problemáticas relacionadas ao aquecimento global, aos resíduos, à poluição e contaminação de recursos hídricos, entre outras, conquistaram um espaço crescente na mídia, em discussões, em pesquisas e em eventos realizados por diferentes setores da sociedade.

Frente a esse cenário, inúmeros esforços têm sido realizados para o enfrentamento dessas questões, contudo, a complexidade da situação atual demanda ações efetivas que produzam maior impacto na realidade mundial. As atividades de Educação Ambiental ${ }^{4}$ despontam como alternativas, uma vez que podem ser utilizadas como importantes ferramentas para o enfrentamento de problemáticas que afetam o meio ambiente e a sociedade como um todo.

A Educação Ambiental é caracterizada pela transversalidade, interdisciplinaridade, pluralidade de manifestações. Ela vem sendo desenvolvida em contextos educacionais, quer sejam formais, não formais e informais e por meio de diversas abordagens. Entre essas abordagens, as atividades de Educação Ambiental realizadas em conjunto com atividades ao ar livre ${ }^{5}$ ou simplesmente atividades de Educação Ambiental ao ar livre podem ser consideradas iniciativas educacionais de sucesso. Nesse sentido, corroboram Louv (2011), Sobel (2005) e Cobb (2004) ao afirmarem que o tempo utilizado pelos indivíduos em atividades realizadas em contato direto com a natureza é um dos aspectos essenciais para o desenvolvimento de um relacionamento positivo.

As atividades de Educação Ambiental ao ar livre integram atividades teóricas a atividades ao ar livre. Entre as atividades teóricas figuram palestras, apresentações, debates, leituras e seminários, os quais são recursos presentes em abordagens tradicionais de Educação Ambiental. Já as atividades ao ar livre são exemplificadas pelo trekking, canoagem, ciclismo, piquenique, acampamento, yoga e jogos de sensibilização, as quais despertam o interesse da população ${ }^{6}$, possuem potencialidades ${ }^{7}$ e requerem atenção diferenciada em relação a questões éticas, em especial, devido à presença de riscos.

\footnotetext{
${ }^{4}$ A educação ambiental possui diversas conceituações, como a presente na Resolução do Conselho Nacional de Educação que trata do tema e pode ser conferida a seguir: "A educação ambiental é uma dimensão da educação, é atividade intencional da prática social, que deve imprimir ao desenvolvimento individual um caráter social em sua relação com a natureza e com os outros seres humanos, visando potencializar essa atividade humana com a finalidade de torná-la plena de prática social e de ética ambiental" (BRASIL, 2012).

50 termo atividades ao ar livre (outdoor activities) é uma das formas mais empregadas internacionalmente para descrever um amplo conjunto de atividades esportivas, físicas, recreativas e educacionais que são realizadas em ambientes ao ar livre.

${ }^{6} \mathrm{O}$ interesse por atividades ao ar livre se relaciona com a presença de conquistas, satisfação, exposição a situações de risco gerenciado, possibilidade de aprendizados, contato com a natureza, entre outros (MANNING, 2011).
} 
Em relação aos riscos presentes em atividades de Educação Ambiental ao ar livre, esses podem se relacionar com incidentes, acidentes e quase perdas, como descreve Attarian (2012): incidentes são condições ou eventos pouco significativos; acidentes são incidentes que ocorrem de forma inesperada e não intencional, normalmente resultando em dano ou lesão; quase perdas são eventos não planejados que não resultam em danos ou lesões, mas possuem o potencial para tanto.

Durante a realização de atividades de Educação Ambiental ao ar livre em conjunto com diversão, descobertas, aventuras e aprendizados podem ocorrer: incidentes, como queimaduras leves por exposição ao sol e pequenos arranhões; acidentes, como torções e crises alérgicas; além de quase perdas que são exemplificadas por situações em que os participantes poderiam ter se lesionado ou se perdido.

A possibilidade desses eventos negativos não deve impedir a realização das atividades educacionais; entretanto, geram a demanda pelo emprego de abordagens estruturadas de gestão de riscos que vão além da simples intencionalidade de realizar atividades seguras. De fato, o tema gestão de riscos em atividades de Educação Ambiental ao ar livre integra iniciativas desenvolvidas por instituições de referência na área ${ }^{8}$, tem sido tratado em obras produzidas em outros países que abordam diversos aspectos dessas atividades educacionais ${ }^{9}$, mas ainda é pouco presente em discussões realizadas no Brasil.

Este relato trata das experiências de gestão de riscos em atividades de Educação Ambiental ao ar livre realizadas em disciplinas dos cursos de Educação Física da Pontifícia Universidade Católica do Rio Grande do Sul (PUCRS) e da Universidade Federal do Rio Grande do Sul (UFRGS). Para uma melhor compreensão, o texto está organizado em três partes. A primeira voltase para a gestão de riscos em atividades ao ar livre, onde são tratados conceitos, fatores e abordagens. A segunda parte descreve aspectos das disciplinas, da gestão de riscos em passos de uma típica saída de campo e de resultados obtidos. Por fim, são apresentadas algumas considerações complementares, além de perspectivas e desdobramentos das atividades.

\section{Gestão de Riscos em Atividades ao Ar Livre}

As iniciativas para reduzir a exposição dos praticantes de atividade ao ar livre a riscos desnecessários são encontradas em diferentes esferas. Em âmbito internacional podem ser citadas as campanhas da American Canoe Association para a promoção da gestão de riscos entre praticantes de

\footnotetext{
7 As potencialidades podem ser organizadas em: aspectos ambientais, como a valorização do meio ambiente e da ética ambiental; aspectos pessoais, em que figura a melhoria da qualidade de vida; aspectos socioculturais, como a ampliação da coesão social; aspectos econômicos, em que se destacam a redução de gastos com saúde e a ampliação das oportunidades de emprego (MANNING, 2011).

8 A gestão de riscos é corriqueira em iniciativas educacionais desenvolvidas pelas instituições National Outdoor Leadership School (NOLS), Outward Bound, Boys Scouts of America, entre outras.

${ }^{9}$ Sugere-se a leitura de Moore (2014) e Danks e Schoefield (2011).

Revbea, São Paulo, V. 11, No 4: 100-116, 2016.
} 
canoagem (AMERICAN CANOE ASSOCIATION, 2015), além dos cursos de formação e conferência específica sobre o tema, realizados pela National Outdoor Leadership School (NOLS, 2016). No Brasil podem ser citadas ações do Ministério do Esporte, como a inclusão do tema gestão de riscos em materiais didáticos e em atividades de capacitação de profissionais que atuam com esportes e atividades ao ar livre (CAVASINI et. al., 2014; CAVASINI; PETERSEN; PETKOWICZ, 2013). Essas iniciativas partilham objetivos quanto à busca pela ampliação da eficiência na gestão de riscos em atividades ao ar livre. A seguir são tratados aspectos relacionados aos riscos, fatores, gestão e abordagem em passos, que são essenciais para a promoção de propostas estruturadas de gestão de riscos em atividades ao ar livre.

De acordo com Federação Britânica de Canoagem, os riscos podem ser compreendidos como a possibilidade, grande ou pequena, de alguém sofrer algum tipo de dano em virtude de um perigo (BRITISH CANOEING, 2014). Em uma conceituação presente na ISO 31000 / ASNZS 2009, os riscos são tratados como "o efeito da incerteza sobre os objetivos" (DICKSON, 2012), ou seja, se relacionam diretamente com aspectos que podem impossibilitar que objetivos existentes em qualquer atividade ao ar livre, como a manutenção da segurança dos praticantes, sejam atingidos. Além disso, Brymer e Gray (2012) salientam que os riscos são frequentemente tratados quanto a aspectos físicos, mas eles também se relacionam com aspectos psicológicos, emocionais e sociais.

Os riscos podem ser tipificados da seguinte forma: riscos reais são os riscos existentes em determinado momento da atividade ao ar livre; riscos subjetivos ou percebidos se relacionam com a avaliação subjetiva do praticante de atividades ao ar livre sobre os riscos existentes a qualquer momento (HADDOCK, 1993 apud DICKSON, 2012; BARTON, 2007); riscos inerentes são os riscos que não podem ser eliminados sem alterar a natureza da atividade (ATTARIAN, 2012); riscos aceitáveis se relacionam com o máximo nível de riscos que são socialmente e eticamente aceitos na execução de atividades ao ar livre (KOSSEFF, 2010). Além disso, os riscos devem ser compreendidos como probabilidades, isto é, a possibilidade de algo acontecer e consequências que são os impactos ou resultados de um determinado evento (STANDARDS NEW ZEALAND, 2004; GWA, 2003; FITZGERALD, 2003; PARKIN; BLADES, 1998).

Os fatores de risco são os elementos que contribuem para elevar a probabilidade do acontecimento de incidentes e acidentes, sendo que os eventos mais graves costumam resultar da combinação desses fatores (ATTARIAM, 2012). Uma das classificações mais tradicionais de fatores de risco busca organizá-los em torno de:

- Equipamentos em que figuram os acessórios e roupas (ex.: casaco impermeável, chapéu, protetor solar, calçados, etc.), materiais (ex.: equipamentos auxiliares de flutuação, capacetes, mochilas, etc.), embarcações/pranchas (ex.: caiaques, pranchas de stand up paddle e de surfe, etc.), sistemas de comunicação e navegação (ex.: rádios VHF,

revista brasileira educação ambiental 
celulares, GPS, etc.).

-Praticantes em que destacam-se as competências (ex.: formação acadêmica, expertise, etc.), saúde, preparo físico, idade, tamanho e características do grupo. Em relação aos

- Ambientes, como as condições meteorológicas e climáticas (ex.: condições indicadas pelas previsões meteorológicas, além de médias históricas de temperatura, ventos, chuvas, etc.), locais empregados para as atividades em terra (ex.: acessos, áreas construídas, espaços ao ar livre, encontro com animais silvestres, presença de pessoas estranhas, etc.) e locais empregados para as atividades na água (ex.: correnteza, maré, profundidade, condições de balneabilidade, turbidez, presença de canais de navegação, etc.).

A presença de riscos não impede a realização de atividades ao ar livre, pois os riscos são inerentes a essas atividades e também se relacionam a aspectos potenciais e motivacionais; entretanto, geram a necessidade da aplicação de propostas de gestão. Nesse sentido, a gestão de riscos é descrita por Dickson (2012) como um conjunto coordenado de atividades e métodos que são empregados para dirigir uma instituição, tratando de riscos que podem afetar a capacidade de atingir objetivos estabelecidos. Para Attarian (2012) a gestão de riscos é "a aplicação sistemática de políticas de gestão, normas e procedimentos para identificar, analisar, avaliar, tratar e monitorar riscos".

Entre as propostas de gestão de riscos em atividades ao ar livre pode ser destacada a ISO 31000 / ASNZS 2009. Essa proposta foi elaborada em conjunto por órgãos Australianos e Neozelandeses e figura entre as utilizadas por instituições de prestígio na área. De acordo com Cavasini, Petersen e Petkowicz (2013) e Dickson (2012), essa proposta pode ser sintetizada pela Figura 1 e descrição que seguem:

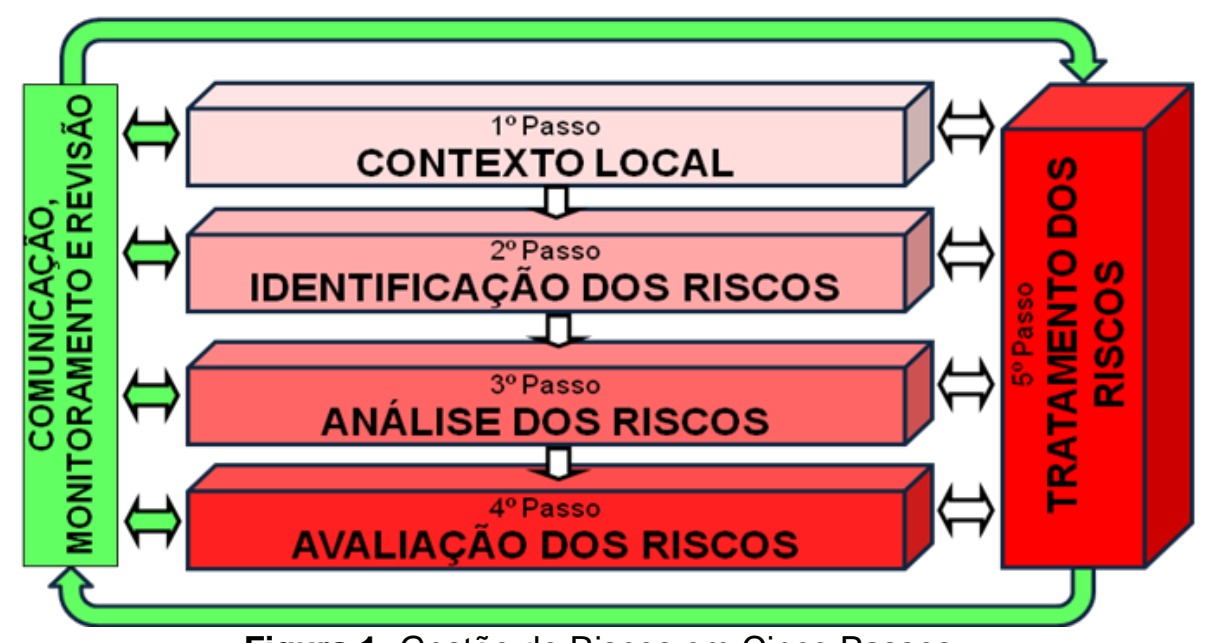

Figura 1: Gestão de Riscos em Cinco Passos.

Fonte: Elaborada pelos autores. 
10 Passo: Contexto local - foca em levantamentos básicos como: as atividades que serão desenvolvidas (ex.: canoagem, surfe, trekking, piquenique, acampamento, observação da natureza, mountain bike, jogos de sensibilização, etc.); existência de normas ou leis que padronizem as atividades (ex.: demanda por formação acadêmica); praticantes (ex.: professores, monitores, alunos, voluntários, etc.); período (ex.: época do ano, horário do dia, etc.); espaços (ex.: lagoas, rios, trilhas, praias, etc.); recursos disponíveis (ex.: humanos, materiais, financeiros, etc.).

2o Passo: Identificação - trata do que pode acontecer (ex.: listar possíveis eventos que possam afetar os objetivos, como incidentes e acidentes) e das razões desses eventos (ex.: listar possíveis causas e cenários). Para produzir uma lista de riscos existentes, salienta-se que podem ser necessários esforços consideráveis para a realização desses questionamentos devido à amplitude de cada aspecto; entretanto, esse passo é essencial para o processo de gestão de riscos, mesmo que sejam geradas amplas listagens.

30 Passo: Análise - busca determinar as consequências (resultados) e as probabilidades (chances) de ocorrência dos riscos identificados anteriormente. Salienta-se que as consequências podem ser organizadas como insignificantes, reduzidas, moderadas, críticas e catastróficas, ao passo que as probabilidades podem ser organizadas em remotas, improváveis, ocasionais, prováveis e frequentes.

40 Passo: Avaliação - busca determinar os riscos aceitáveis que podem ser tratados por procedimentos adequados de gerenciamento e os riscos inaceitáveis, os quais podem impedir a realização de atividades ao ar livre.

5o Passo: Tratamento - frente à identificação, análise e avaliação dos riscos, busca tomar decisões, as quais devem ser empregadas em conjunto e que podem ser organizadas em cinco estratégias de tratamento.

- Reduzir as probabilidades que pode ser exemplificado pelo uso de equipamentos auxiliares de flutuação em atividades realizadas na água para reduzir a probabilidade de afogamento ou pela escolha de um percurso de trekking, de acordo com as características do grupo;

- Reduzir as consequências, como o uso de capacete para reduzir os riscos de traumatismo craniano e utilização de roupas de neoprene para colaborar com a manutenção da temperatura corporal;

- Aceitar os riscos que são esperados durante a prática de atividades ao ar livre estruturadas;

- Evitar os riscos, como ocorre ao cancelar a atividade programada devido a condições meteorológicas desfavoráveis ou por demanda de competências superiores às possuídas pelos praticantes;

- Transferir os riscos, em que figuram contar com terceiros para a realização de atividades ou quando são contratadas apólices de seguro. 
Comunicação, monitoramento e revisão - ressalta a necessidade dos envolvidos com atividades ao ar livre promoverem constantes trocas de informações e atividades avaliativas. Além disso, busca a valorização das opiniões de pessoas com expertise na área, inclusive, externas às instituições. Salienta-se que esses aspectos são essenciais para a busca de uma eficaz gestão de riscos, por permitir uma rápida adaptação a quaisquer mudanças, bem como o aprimoramento das propostas em execução.

A gestão de riscos se relaciona com a manutenção de um equilíbrio entre o nível de risco associado com as atividades desenvolvidas e os objetivos existentes (ex.: desenvolvimento de atitudes e conhecimento ambientalmente relevantes), em que a segurança dos participantes deve ser o objetivo mais relevante e anterior aos demais. As propostas coerentes de gestão de riscos em atividades de Educação Ambiental ao ar livre são aquelas em que os objetivos podem ser maximizados e os riscos desnecessários e efeitos negativos minimizados. Dessa forma, a gestão de riscos não deve ser compreendida como uma simples listagem ou documento único e estático, mas como um esforço permanente para a construção de competências e de uma cultura de segurança.

\section{A Abordagem de Gestão de Riscos em Atividades de Educação Ambiental}

A abordagem de gestão de riscos em atividades de Educação Ambiental ao ar livre desse relato é desenvolvida na Faculdade de Educação Física e Ciências do Desporto da PUCRS desde 2011. As experiências são organizadas em torno da disciplina Esportes na Natureza, a qual possui carga horária de 32 horas/aula, estruturadas em encontros de duas, quatro e seis horas/aula. Essa disciplina é proposta todos os semestres e normalmente são oferecidas duas turmas. Por sua vez, na Escola de Educação Física da UFRGS a disciplina Tópicos Especiais em Esporte 3 - Atividades Esportivas e Educacionais na Natureza é oferecida desde 2013, possui carga horária de 64 horas/aula, organizadas em encontros de dois, quatro e oito horas/aula. Essa disciplina possui caráter diferenciado, com apenas uma turma oferecida por semestre. Salienta-se que ambas as disciplinas possuem caráter teóricoprático e objetivam desenvolver conhecimento relacionado aos esportes e atividades ao ar livre, à Educação Ambiental ao ar livre, à gestão de riscos, à ética em atividades ao ar livre, aos locais empregados para a prática, bem como atividades experienciais ${ }^{10}$.

O grupo de participantes é formado por professores universitários, alunos e convidados. Os docentes que atuam nas disciplinas são graduados

\footnotetext{
10 As atividades experienciais se relacionam com a aprendizagem e educação experienciais. A aprendizagem experiencial é uma forma de aprendizado autêntica, baseada nos sentidos (BEHRENDT; FRANKLIN, 2014) e que compreende: "o processo de aprendizagem oriundo diretamente de experiências vivenciadas pelos alunos" (ITIN, 1999). Já a educação experiencial pode ser conceituada como uma metodologia em que educadores, premeditadamente, levam os alunos a experiências e a reflexões com o intuito de desenvolver conhecimento, habilidades, valores e capacidades relevantes para a atuação e contribuição em suas comunidades (ASSOCIATION FOR EXPERIENTIAL EDUCATION, 2016; 1994).

Revbea, São Paulo, V. 11, № 4: 100-116, 2016.
} 
em Educação Física, especialistas em Educação Ambiental, alunos do Programa de Pós-Graduação em Ciências do Movimento Humano da UFRGS e possuem expertise nas áreas de esportes e atividades ao ar livre, Educação Ambiental, gestão riscos, projetos esportivos sociais e educação ao ar livre. Os alunos são oriundos de cursos de graduação e pós-graduação em Educação Física, Pedagogia, Nutrição, Geografia, Administração de Empresas, Engenharias, Biologia, Química, entre outros. É característica de grande parte dos alunos possuir nenhuma ou reduzidas experiências anteriores relacionadas aos temas propostos pelas disciplinas. Somam-se ao grupo, professores convidados os quais colaboram com expertise nas áreas de interesse das disciplinas, em especial, durante as saídas de campo e atividades experienciais.

A abordagem de gestão de riscos em cinco passos é empregada por professores e alunos para o planejamento, execução e avaliação de todas as atividades de Educação Ambiental ao ar livre. Nesse sentido, as figuras e as descrições a seguir focam em atividades educacionais realizadas durante saídas de campo em áreas do Parque Natural Morro do Osso ${ }^{11}$.

O primeiro passo da gestão de riscos busca definir aspectos básicos que exercem um papel orientador aos demais. Em relação à saída de campo citada, diversos aspectos podem ser levantados: as atividades realizadas são trekking, leitura de materiais, discussões, observação da natureza e de impactos ambientais presentes nos locais, Workshop de Conscientização Não Deixe Rastro (Leave no Trace Awareness Workshop) ${ }^{12}$ e piquenique; os participantes são professores universitários, alunos de graduação e pósgraduação e convidados, em grupos de 12 a 20 indivíduos; as áreas empregadas são zonas de uso intensivo da unidade de conservação, como as trilhas do Eixo Central e de acesso ao Pé-de-Deus e ao topo do morro, conhecido por Platô; as atividades ocorrem nos meses de março e setembro, nos turnos da manhã ou tarde e com duração de aproximadamente quatro horas; a metodologia possui caráter experiencial.

O segundo passo aborda possíveis acidentes e incidentes, listando os riscos existentes, por meio de técnicas de levantamento de informações. Quanto às atividades de Educação Ambiental ao ar livre, são realizados levantamentos de dados com pessoas que conheçam o local, em documentos, na internet e durante a própria saída. Desse modo, contribui-se com elementos às discussões que apontam para diversos riscos nas atividades desenvolvidas nas disciplinas, como os seguintes: hipotermia, crise alérgica, desidratação, torções, quedas, queimaduras por exposição ao sol, desentendimentos entre

\footnotetext{
${ }^{1}$ Entre os locais empregados para a realização de saídas de campo podem ser destacadas a já citada unidade de conservação Parque Natural Morro do Osso e a Reserva da Vida Silvestre Morro Santana, ambas em Porto Alegre (CAVASINI; BREYER, 2015).

12 O Workshop de Conscientização Não Deixe Rastro é uma proposta de educação ambiental ao ar livre focada nos Leave no Trace Principles (Princípios de Não Deixar Rastro) desenvolvida pela The Leave no Trace - Center for Outdoor Ethics. Essa proposta centra-se no desenvolvimento de competências, atitudes e de aspectos éticos relevantes para a minimização de impactos ambientais em atividades ao ar livre (LNT, 2016; CAVASINI; BREYER, 2015).
}

revista brasileira educação ambiental 
os participantes ou com terceiros, assaltos, furtos, agressões realizadas por terceiros e se perder nas trilhas e áreas visitadas.

A Figura 2 sumariza os dois primeiros passos da gestão de riscos.

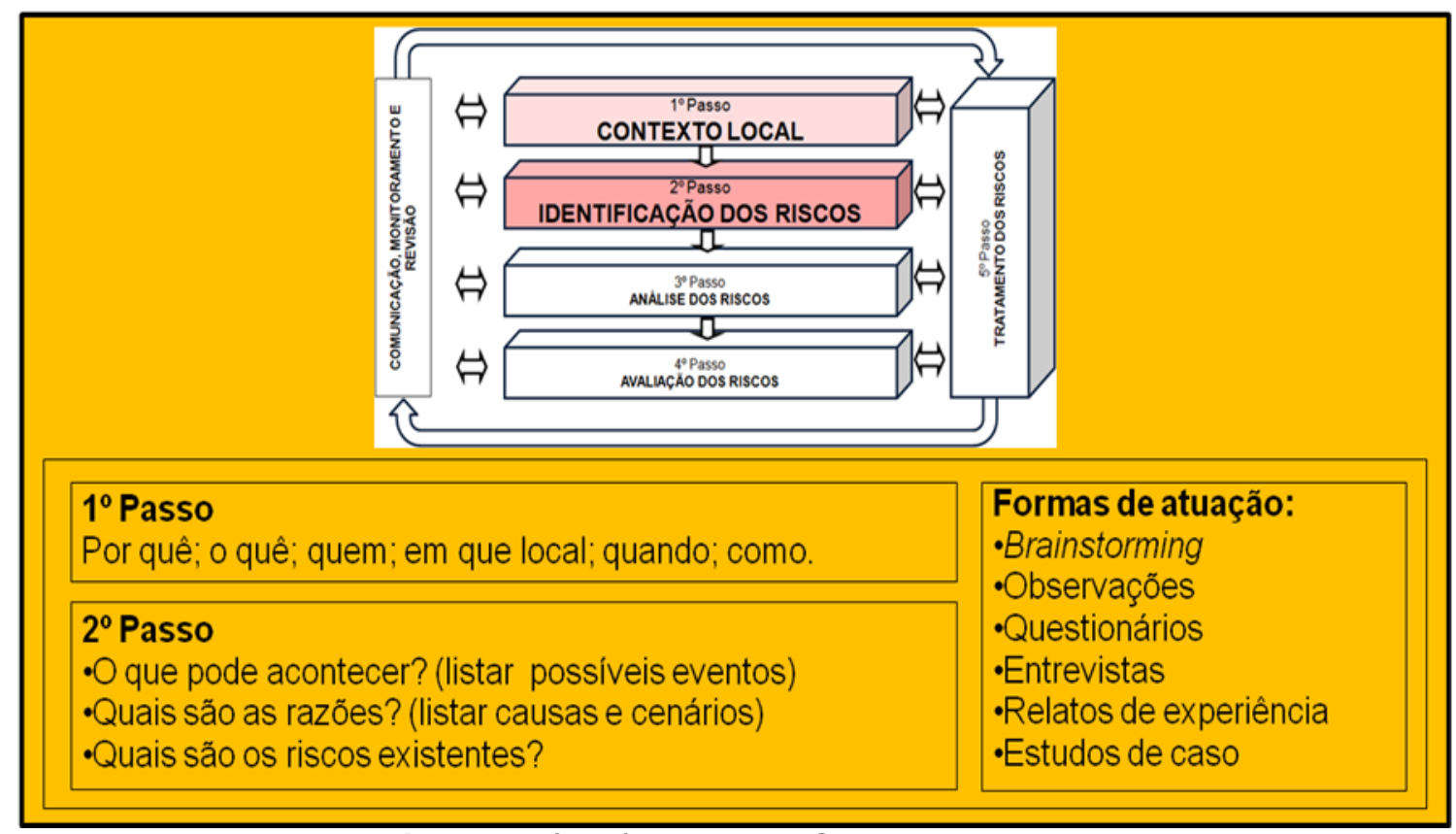

Figura 2: $1^{\circ}$ e $2^{\circ}$ Passos da Gestão de Riscos.

Fonte: Elaborada pelos autores.

O terceiro passo busca classificar os riscos identificados anteriormente, de acordo com suas consequências e probabilidades. Em relação à saída de campo na unidade de conservação foram determinadas consequências ${ }^{13} \mathrm{e}$ probabilidades que estão descritas dentro dos parênteses:

- queimaduras por exposição ao sol (insignificantes/reduzidas improvável);

- hipotermia (reduzidas/moderadas - improvável);

- desidratação (insignificantes/reduzidas - ocasional);

- torções (reduzidas/moderadas - ocasional);

- quedas (reduzidas/moderadas - ocasional);

- crise alérgica (insignificantes/catastróficas - ocasional);

${ }^{13}$ Salienta-se que as consequências de qualquer risco são específicas para cada situação e podem variar em termos de expressividade. Por exemplo, o risco de queimaduras por exposição ao sol pode ser catastrófico em atividades realizadas por longos períodos e em ambientes extremos, ao passo que, na saída de campo relatada as consequências variam de insignificantes a reduzidas.

Revbea, São Paulo, V. 11, № 4: 100-116, 2016. 
- desentendimentos entre os participantes ou com terceiros (reduzidas/moderadas - improvável);

- assalto (insignificantes/catastróficas - remota);

- furto (insignificantes/moderadas - improvável);

-agressões realizadas por terceiros (insignificantes/catastróficas remota);

- perder-se nas trilhas e áreas visitadas (insignificantes/reduzidas improvável).

O quarto passo categoriza os riscos analisados anteriormente, em termos de riscos reduzidos $(R)$, medianos (M), significativos $(S)$ ou extremos (E), desse modo, buscando determinar a atenção que deve ser atribuída a cada um desses:

- queimaduras por exposição ao sol (R);

- hipotermia (R/M);

- desidratação (R);

- torções (M/S);

- quedas (M/S);

- crise alérgica (R/M/S/E);

- desentendimentos entre os participantes ou com terceiros (R/M);

- assalto (R/M/S);

- furto (R/M);

- agressões realizadas por terceiros (R/M/S);

- perder-se nas trilhas e áreas visitadas $(\mathrm{R})$.

A Figura 3 apresenta os principais aspectos do terceiro e do quarto passos da gestão de riscos. 


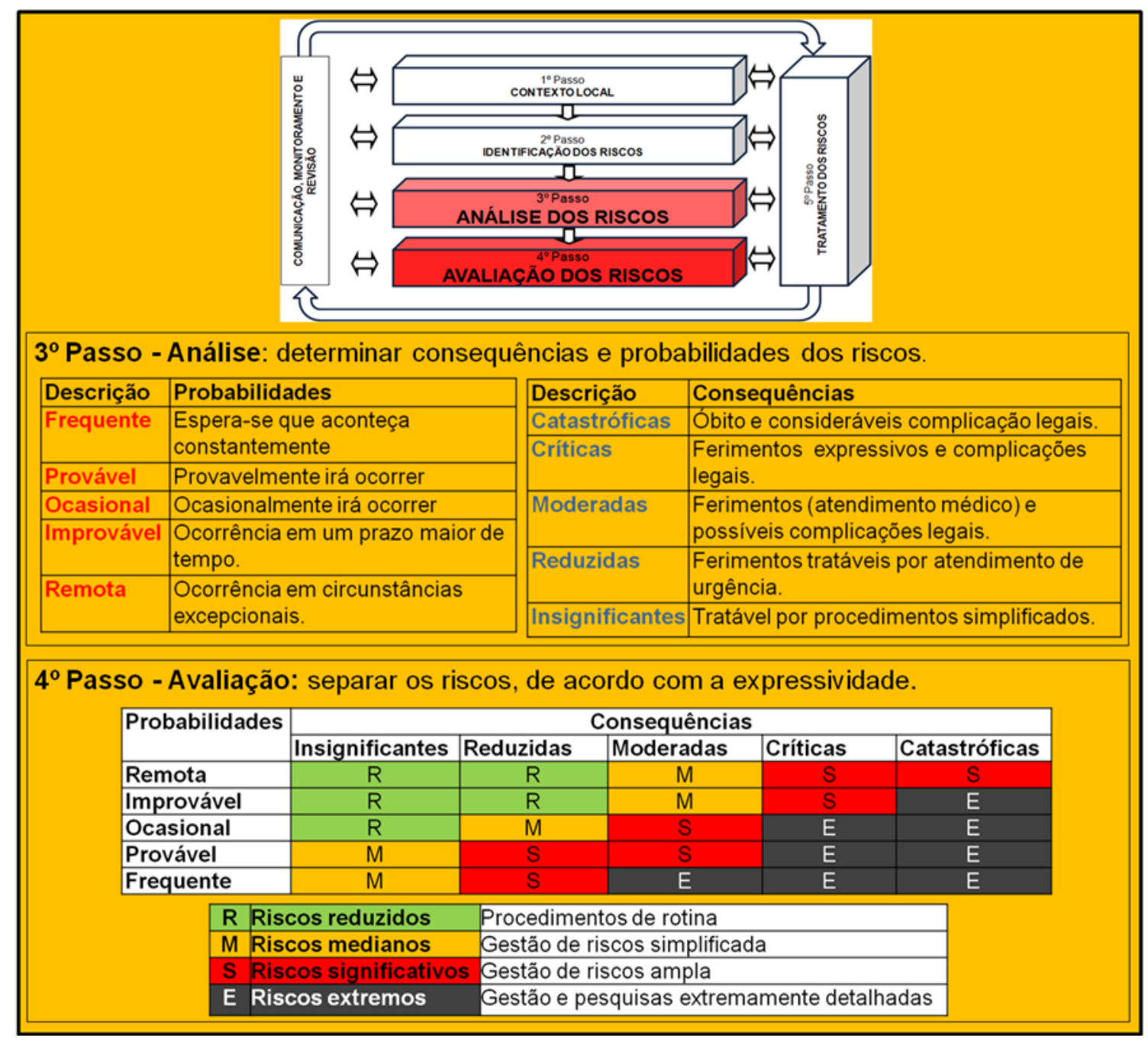

\begin{tabular}{|c|c|c|c|}
\hline Descrição & Probabilidades & Descrição & Consequências \\
\hline \multirow[t]{2}{*}{ Frequente } & \multirow{2}{*}{$\begin{array}{l}\text { Espera-se que aconteça } \\
\text { constantemente }\end{array}$} & Catastróficas & Óbito e consideráveis complicação legais. \\
\hline & & \multirow[t]{2}{*}{ Críticas } & \multirow{2}{*}{$\begin{array}{l}\text { Ferimentos expressivos e complicaçőes } \\
\text { legais. }\end{array}$} \\
\hline Provável & Provavelmente irá ocorrer & & \\
\hline Ocasional & Ocasionalmente irá ocorrer & \multirow[t]{2}{*}{ Moderadas } & \multirow{2}{*}{$\begin{array}{l}\text { Ferimentos (atendimento médico) e } \\
\text { possíveis complicações legais. }\end{array}$} \\
\hline \multirow[t]{2}{*}{ Improvável } & \multirow{2}{*}{$\begin{array}{l}\text { Ocorrência em um prazo maior de } \\
\text { tempo. }\end{array}$} & & \\
\hline & & \multirow[t]{2}{*}{ Reduzidas } & \multirow{2}{*}{$\begin{array}{l}\text { Ferimentos tratáveis por atendimento de } \\
\text { urgência. }\end{array}$} \\
\hline \multirow[t]{2}{*}{ Remota } & \multirow{2}{*}{$\begin{array}{l}\text { Ocorrência em circunstâncias } \\
\text { excepcionais. }\end{array}$} & & \\
\hline & & Insignificantes & Tratável por procedimentos simplificados. \\
\hline
\end{tabular}

$4^{\circ}$ Passo - Avaliação: separar os riscos, de acordo com a expressividade.

\begin{tabular}{|l|c|c|c|c|c|}
\hline \multirow{2}{*}{ Probabilidades } & \multicolumn{5}{|c|}{ Consequências } \\
\cline { 2 - 6 } & Insignificantes & Reduzidas & Moderadas & Críticas & Catastróficas \\
\hline Remota & $\mathrm{R}$ & $\mathrm{R}$ & $\mathrm{M}$ & $\mathrm{S}$ & $\mathrm{S}$ \\
\hline Improvável & $\mathrm{R}$ & $\mathrm{R}$ & $\mathrm{M}$ & $\mathrm{S}$ & $\mathrm{E}$ \\
\hline Ocasional & $\mathrm{R}$ & $\mathrm{M}$ & $\mathrm{S}$ & $\mathrm{E}$ & $\mathrm{E}$ \\
\hline Provável & $\mathrm{M}$ & $\mathrm{S}$ & $\mathrm{S}$ & $\mathrm{E}$ & $\mathrm{E}$ \\
\hline Frequente & $\mathrm{M}$ & $\mathrm{S}$ & $\mathrm{E}$ & $\mathrm{E}$ & $\mathrm{E}$ \\
\hline
\end{tabular}

Figura 3: $3^{\circ}$ e $4^{\circ}$ Passo da Gestão de Riscos.

Fonte: Elaborada pelos autores.

O quinto passo busca a tomada de ação, frente ao desenvolvido nos passos anteriores, conforme segue.

- redução de probabilidades: queimaduras por exposição ao sol (escolha de horário adequado de realização das atividades e utilização de protetor solar e vestuário apropriado); hipotermia (escolhas adequadas da época do ano e horário da realização das atividades, bem como uso de vestuário apropriado); desidratação (ingestão de líquidos); torções (utilização de calçados adequados); quedas (emprego de trilhas e locais estabelecidos para as atividades); crise alérgica (levantamento de informações, anteriormente à saída de campo, sobre casos específicos ou extremos, além de evitar o contato com elementos alergênicos); desentendimentos entre os participantes ou desses com terceiros (desenvolvimento de competências de trabalho em equipe e de liderança); assalto (notificar antecipadamente os responsáveis pela área sobre a realização de atividades e a escolha de horário); furto (manter atenção sobre os itens 
pessoais); agressões realizadas por terceiros (notificar antecipadamente os responsáveis pela área sobre a realização de atividades e a escolha horário); se perder nas trilhas e áreas visitadas (desenvolvimento de competências e uso de equipamentos de navegação, além de permanecer nos locais determinados para as atividades).

- redução de consequências: assalto e agressões realizadas por terceiros (notificar autoridades, instituições e demais envolvidos sobre o ocorrido, além de buscar atendimento médico de urgência, caso seja necessário); furto (notificar autoridades, instituições e demais envolvidos sobre 0 ocorrido); desentendimentos entre os participantes ou desses com terceiros (emprego de técnicas para resolução de conflitos); torções e quedas (buscar atendimento médico de urgência); crise alérgica (buscar atendimento médico de urgência e deslocamento à local de atendimento de urgência); se perder nas trilhas e áreas visitadas (desenvolvimento de competências e uso de equipamentos de navegação e comunicação).

- aceitação dos riscos: como ocorre durante a prática de atividades ao ar livre realizada de forma eticamente comprometida e em que todos são corresponsáveis pela gestão de riscos;

- evitar os riscos: quando as condições meteorológicas são impeditivas e a saída de campo é cancelada;

- transferência dos riscos: se relaciona com a contratação de apólice de seguro e de empresas de transporte.

Além disso, torna-se relevante salientar que qualquer processo de gestão de riscos possui demandas constantes de comunicação, monitoramento e revisão. Em relação à comunicação, professores, alunos e convidados trocam informações constantemente e são coparticipantes em todas as etapas da gestão de riscos empregada. No que se refere ao monitoramento e revisão, a abordagem de gestão de riscos em atividades de Educação Ambiental ao ar livre é desenvolvida de acordo com cada grupo, considerando seus integrantes, locais empregados, condições climáticas e as previsões meteorológicas, as quais são constantemente alteradas.

A Figura 4 sumariza o quinto passo, a comunicação, o monitoramento e a revisão da Gestão de Riscos. 


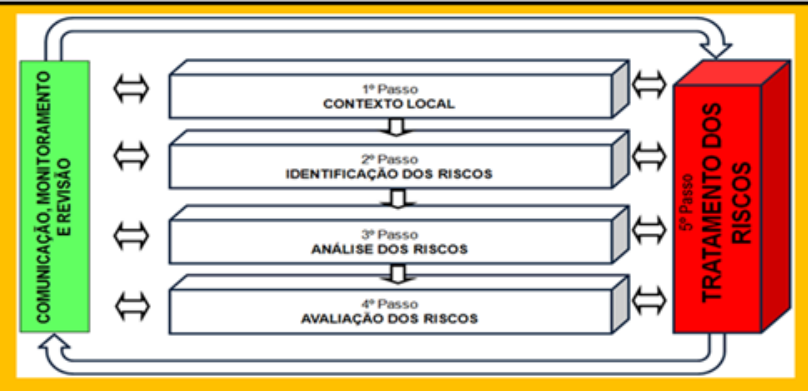

$5^{\circ}$ Passo - Tratamento: tomada de ação que resultou da identificação e avaliação dos riscos, considerados inaceitáveis ou elevados para uma organização ou grupo de pessoas.

Possibilidades: Reduzir probabilidades, reduzir consequências, aceitar os riscos, evitar os riscos, transferir os riscos

Comunicação, Monitoramento e Revisão: Comunicação eficiente é necessária para assegurar que todos os envolvidos estejam cientes de seus papéis e responsabilidades. A gestão de riscos é um processo dinâmico e deficiências na comunicação, monitoramento e revisão podem criar um ambiente propício para a ocorrência de incidentes e acidentes.

Figura 4: 5ำ Passo, Comunicação, Monitoramento e Revisão da Gestão de Riscos Fonte: Elaborada pelos autores

As avaliações sobre o desenvolvimento do tema gestão de riscos em atividades de Educação Ambiental ao ar livre têm apontado para diversos aspectos, os quais podem ser categorizados em dois blocos. O primeiro é vinculado às disciplinas e se relaciona com o aprimoramento do processo de gestão de riscos em atividades de Educação Ambiental ao ar livre que pode ser exemplificado pela inexistência de acidentes ou incidentes graves em mais de uma centena de saídas de campo realizadas. Além disso, torna-se relevante salientar que essa proposta de gestão de riscos em atividades de Educação Ambiental ao ar livre tem servido de modelo para o planejamento e execução de propostas educacionais realizadas fora das disciplinas e, inclusive, por outras instituições.

O segundo bloco é voltado aos alunos e se relaciona com o seguinte: ampliação do conhecimento, da percepção de relevância e do interesse para a promoção dos temas gestão de riscos e Educação Ambiental ao ar livre; ampliação do interesse para a realização de pesquisas; promoção de iniciativas de gestão de riscos em atividades ao ar livre e de Educação Ambiental em escolas, projetos educacionais, centros esportivos e centros de atividades físicas; desenvolvimento de aspectos relacionados à ética em atividades ao ar livre; ampliação de competências relevantes para a gestão de riscos em atividades de Educação Ambiental ao ar livre; valorização dos espaços ao ar livre empregados para o desenvolvimento das atividades experienciais, em especial, de áreas das unidades de conservação visitadas. 


\section{Outras Considerações e perspectivas}

As atividades de Educação Ambiental ao ar livre, ao mesmo tempo em que despertam o interesse da população e permitem o desenvolvimento de atividades educacionais diferenciadas, podem expor professores, alunos e demais envolvidos a riscos desnecessários. Desse modo, gera-se a demanda por esforços estruturados de gestão que superem a simples intencionalidade de promover atividades educacionais seguras.

Outras questões que merecem a atenção quanto à gestão de riscos em atividades de Educação Ambiental ao ar livre são as percepções dos participantes sobre os riscos, o emprego de tecnologias, níveis de gestão e ações que devem ser tomadas em caso de acidentes. As percepções de professores, alunos e convidados podem influenciar negativamente a habilidade de avaliar as situações que serão experienciadas, uma vez que, ao se subestimar ou superestimar um risco devido à falta de expertise, eleva-se a probabilidade de ocorrência de julgamentos incorretos, incidentes e acidentes. Dessa forma e como sugere Leemon (2005), o desenvolvimento de competências que contribuam para a avaliação mais efetiva dos riscos existentes é um aspecto essencial para a gestão de riscos nessas atividades.

O emprego de tecnologias ${ }^{14}$ em atividades de Educação Ambiental ao ar livre, além de estar em sintonia com anseios atuais de boa parte da população, pode contribuir para a gestão de riscos e obtenção dos objetivos estabelecidos. De acordo com Neill e Gray (2012) diferentes tecnologias podem se relacionar com a ampliação do conforto (ex.: óculos de sol, calçados específicos para cada atividade), segurança (ex.: cordas, comunicadores, equipamentos à prova d'água e quedas), proteção (ex.: capacetes, equipamentos auxiliares de flutuação), formação (ex.: livros, cursos, atividades), além do aprimoramento do transporte aos locais de prática (ex.: veículos automotores, trilhas demarcadas) e da navegação (ex.: bússola, GPS, mapas). Entretanto essas tecnologias podem contribuir para a redução da qualidade do contato com a natureza (ex.: uso de jogos eletrônicos, conferência de redes sociais e troca de informações com terceiros durante as atividades educacionais) e para tomadas de decisão inadequadas (ex.: supervalorização de equipamentos e descaso com demais fatores humanos e ambientais), dessa forma, enfatizando o fato de que 0 emprego de tecnologias em atividades de Educação Ambiental ao ar livre sempre deve possuir orientação ética.

De acordo com Barton (2007) a gestão de riscos pode ser proposta em níveis, como os que seguem: genérico que considera os riscos normalmente esperados em uma determinada atividade (ex.: o risco de afogamento em atividades realizadas próximas ou na água); local que foca nos riscos de uma atividade realizada em um local específico (ex.: profundidade, níveis de poluição, condições das trilhas, etc.); diário que se volta para os riscos de uma

\footnotetext{
14 O termo tecnologia pode ser tratado como o conjunto diversificado de processos, ferramentas e conhecimento utilizados para ampliar as capacidades humanas, facilitar a realização de tarefas e satisfazer necessidades e desejos (ITEA, 2007).
}

revista brasileira educação ambiental 
atividade no dia de sua realização (ex.: condições meteorológicas previstas); dinâmico que foca nos riscos de uma atividade que esteja em execução (ex.: situações problemáticas que possam ocorrer, como desentendimento e desobediência a regras previamente estabelecidas ou legislações existentes).

As atividades de Educação Ambiental ao ar livre possuem riscos que podem ser gerenciados, mas não completamente controlados ou eliminados. Sendo assim, também devem ser consideradas estratégias para tratar de situações relacionadas a acidentes, como os Planos de Resposta de Emergência e Planos de Crises. De acordo com NOLS (2010) e Ajango (2005) os Planos de Resposta de Emergência ${ }^{15}$ relacionam-se com os seguintes aspectos: conhecimento das capacidades e limitações das pessoas e instituições envolvidas na promoção de atividades ao ar livre; estabelecimento de procedimentos eficientes de comunicação, entre todos os envolvidos; eficiência em contatar instituições e pessoas que possam prestar atendimento médico de urgência. Os Planos de Crises $^{16}$ voltam-se para o seguinte: respostas imediatas em caso de acidentes, buscando a segurança de todos, estabilizando e impedindo o agravamento das situações; planos de contingência e evacuação; estratégias de comunicação com outras instituições e pessoas; revisão dos procedimentos e investigação de incidentes e acidentes, de modo a aprimorar a própria gestão de riscos.

Quanto à abordagem de gestão de riscos em atividades de Educação Ambiental ao ar livre desenvolvida nas disciplinas ministradas na PUCRS e na UFRGS, as avaliações apontaram que os envolvidos assimilaram a importância do tema e que a adequada gestão de riscos durante as saídas de campo contribuiu para a não ocorrência de acidentes e incidentes sérios. Enfim, uma abordagem de gestão de riscos em atividades de Educação Ambiental ao ar livre que busca estar em sintonia com o surgimento de novas tecnologias e demandas, ao mesmo tempo em que tem servido de modelo para a elaboração de iniciativas similares em outras instituições.

\section{Referências}

AJANGO, D. Risk Management Planning: A Closer Look. In: AJANGO, D. Lessons Learned II: Using Case Studies and History to Improve Safety Education. Alaska, EUA: SafetyEd, 2005.

AMERICAN CANOE ASSOCIATION. Disponível em: http://www.americancanoe.org/?page=Resources. Acesso em 4 de dezembro de 2015.

ASSOCIATION FOR EXPERIENTIAL EDUCATION. Disponível em: http://www.aee.org/about/whatlsEE, acesso em 2 de janeiro de 2016.

15 Emergência pode ser definida como um evento inesperado que requer uma resposta urgente.

16 Crise pode ser definida como um evento que supera as competências de resposta e os recursos disponíveis no momento de sua ocorrência.

Revbea, São Paulo, V. 11, No 4: 100-116, 2016. 
ASSOCIATION FOR EXPERIENTIAL EDUCATION. AEE Definition of Experiential Education. Boulder, EUA: Association for Experiential Education, 1994.

BARTON, B. Safety, Risk and Adventure in Outdoor Activities. Thousand Oaks, EUA: Sage Publications, 2007.

BRASIL. Resolução no 2, de 15 de junho de 2012. Estabelece as Diretrizes Curriculares Nacionais para a Educação Ambiental. Diário Oficial da União, 16 de junho de 2012.

BRITISH CANOEING. British Canoeing Safety Guidelines for Paddlers, Clubs and Volunteers. Nottingham, Inglaterra: British Canoeing/Canoe England, 2014.

BRYMER, E.; GRAY, T.L. Program Design and Activity Selection. In: DICKSON, T.; GRAY, T. Risk Management in the Outdoors: A Whole of Organization Approach for Education, Sport and Recreation. Melbourne, Austrália: Cambridge University Press, 2012.

CAVASINI, R.; BREYER, R.F. Educação Ambiental ao Ar Livre: Experiências em Unidades de Conservação. Educação Ambiental em Ação, v. 53, 2015.

CAVASINI, R. et al. Práticas Corporais de Aventura. In: OLIVEIRA, A. B.; GONZALES, F. G.; DARIDO, S. (Org.). Lutas, capoeira e práticas corporais de aventura. Maringá: EDUEM, 2014.

CAVASINI, R.; PETERSEN, R.D.S.; PETKOWICZ, F. Projeto PST/Navegar: Aspectos Técnicos e Pedagógicos. Maringa: EDUEM, 2013.

COBB, E. The Ecology of Imagination in Childhood. Putnam, EUA: Spring, 2004.

DANKS, F.; SCHOFIELD, J. Run Wild!: Outdoor Games and Adventures. Londres, Inglaterra: Frances Lincoln, 2011.

DICKSON, T. An Introduction to Risk, Adventure and Risk Management. In: DICKSON, T.; GRAY, T. Risk Management in the Outdoors: A Whole of Organization Approach for Education, Sport and Recreation. Melbourne, Austrália: Cambridge University Press, 2012.

FITZGERALD, P. Risk management guide for tourism operators. Ottawa, Canadá: Canadian Tourism Commission, 2003.

GOVERNMENT OF WESTERN AUSTRALIA (GWA). Can you risk it?: An introduction to risk management for community organizations. Austrália: GWA, 2003.

INTERNATIONAL TECHNOLOGY EDUCATION ASSOCIATION (ITEA). Standards for Technological Literacy: Content for the Study of Technology. Reston, EUA: ITEA, 2007.

ITIN, C.M. Reasserting the Philosophy of Experiential Education as a Vehicle for Change in the 21st Century. The Journal of Experiential Education, n. 22, 1999.

revista brasileira educação ambiental 
KOSSEFF, A. AMC Guide to Outdoor Leadership. Boston, EUA: Appalachian Mountain Club Books, 2010.

LEEMON, D. Understanding "How Accidents Happen" in Outdoor Pursuits. In: AJANGO, D. Lessons Learned II: Using Case Studies and History to Improve Safety Education. Alaska, EUA: SafetyEd, 2005.

LOUV, Richard. Last Child in the Woods: Saving Our Children from NatureDeficit Disorder. Nova lorque, EUA: Workman, 2008.

MANNING, R.E. Studies in Outdoor Recreation: Search and Research for Satisfaction. Corvallis, EUA: Oregon State University Press, 2011.

MOORE, R. Nature Play \& Learning Places: Creating and managing places where children engage with nature. Raleigh, EUA: National Wildlife Federation and Natural Learning Initiative, 2014.

NATIONAL OUTDOOR LEADERSHIP SCHOOL (NOLS). Disponível em http://www.nols.edul. Acesso em 2 de janeiro de 2016.

NATIONAL OUTDOOR LEADERSHIP SCHOOL (NOLS). NOLS Risk Management Training. Lander, EUA: NOLS, 2010.

NEILL, J.T.; GRAY, T.L. Technology, Risk and Outdoor Programming. In: DICKSON, T.; GRAY, T. Risk Management in the Outdoors: A Whole of Organization Approach for Education, Sport and Recreation. Melbourne, Austrália: Cambridge University Press, 2012.

PARKIN, D.; BLADES, G. Risk Management and outdoor education: a practical approach to ensuring positive outcomes. Outdoor Educator's Association of Queensland's journal Horizons, n. 66, 1998.

SOBEL, D. Placed Based Education: Connecting Classrooms and Communities. Great Barrington, EUA: The Orion Society, 2005.

THE LEAVE NO TRACE CENTER FOR OUTDOOR ETHICS (LNT). Disponível em: www.Int.org, acesso em 2 de janeiro de 2016. 